\title{
Serum microRNAs: A new diagnostic method for colorectal cancer (Review)
}

\author{
YI YANG* , XIAODONG GU*, MINWEI ZHOU, JIANBIN XIANG and ZONGYOU CHEN \\ Department of General Surgery, Huashan Hospital, Fudan University, Shanghai 200040, P.R. China
}

Received February 15, 2013; Accepted May 10, 2013

DOI: $10.3892 /$ br.2013.109

\begin{abstract}
Colorectal cancer (CRC) is the third most common malignant tumor worldwide, affecting over 1.23 million individuals annually. Over the past several years, the role of microRNAs (miRNAs) in CRC cells have been extensively investigated. Recently, it was discovered that extracellular miRNAs circulate in the blood of healthy individuals as well as CRC patients. Serum circulating miRNAs as novel biomarkers may be a new approach to CRC diagnosis. However, their secretory mechanism and biological function have not been fully elucidated. In this review, the main serum miRNAs used as potential diagnostic biomarkers for CRC, such as miR-92, miR-141, miR-29a, miR-21, miR-221, miR-601 and miR-760, were summarized. In addition, the mechanism of miRNA secretion from CRC cells was discussed. It is recommended that additional studies focus on the usefulness of serum miRNAs for early CRC diagnosis, prognosis and therapeutics.
\end{abstract}

\section{Contents}

1. Introduction

2. Main serum miRNAs in CRC diagnosis

3. Mechanism of miRNA secretion and incorporation

4. Potential value

5. Limitations

6. Conclusions

\section{Introduction}

Colorectal cancer (CRC) is the third most common malignant tumor worldwide (1). Over 1.23 million individuals are

Correspondence to: Professor Zongyou Chen, Department of General Surgery, Huashan Hospital, Fudan University, 12 Wulumuqi Middle Road, Shanghai 200040, P.R. China

E-mail: zongyouc@sohu.com

*Contributed equally

Key words: diagnosis, colorectal cancer, microRNA diagnosed with CRC and 0.6 million succumb to the disease worldwide annually (2). Early-stage diagnosis of CRC potentially reduces the mortality of this disease (3). Although colonoscopic screening for CRC is currently the most reliable diagnostic tool, its cost and invasive nature limit its use. Thus, there is a pressing need for novel, non-invasive, highly sensitive biomarkers to improve the detection of CRC.

microRNAs (miRNAs) are a class of highly conserved short nucleotide non-coding single-stranded RNA molecules (range, 18-22 nucleotides). miRNAs are involved in the regulation of gene expression through post-transcriptional processing as they suppress translation or induce mRNA degradation (4). Since their discovery in 1993, the altered expression of miRNAs has been associated with cancer. An individual miRNA may affect the expression of various genes and may exert pleiotropic effects on carcinogenesis (5). Overexpression and silencing or switching off of specific miRNAs have been previously described in the carcinogenesis of CRC (6).

High serum concentrations of highly stable, cell-free miRNAs were also identified (7-9). Evidence from a previous study indicated that such miRNAs are secreted into the blood and are involved in regulating the translation of specific protein-coding genes (10). Serum miRNAs may be measured repeatedly and non-invasively in a wide array of cancer types. Previous studies revealed that circulating tumor-associated miRNAs may serve as diagnostic predictors of various types of cancer (11-13). In this review, the potential usefulness of circulating miRNAs in CRC diagnosis was assessed.

\section{Main serum miRNAs in CRC diagnosis}

miR-92. Ng et al (14) were the first to perform a quantitative assessment of miRNAs in CRC. They observed the overexpression of miR-17-3p, miR-135b, miR-222, miR-92 and miR-95 in the preoperative serum samples of CRC patients. Their subsequent study on $90 \mathrm{CRC}$ patients and 50 control subjects demonstrated that expression levels of miR-17-3p and miR-92 was elevated in all the CRC patients $(\mathrm{P}<0.0005)$. The miR-92 sensitivity was $89 \%$ and its specificity was $70 \%$. Huang et al (15) also reported that the sensitivity of miR-92a was $83.0 \%$ and its specificity was $84.7 \%$ in CRC. This indicated that miR-92 may be a non-invasive molecular marker for CRC diagnosis.

miR-141. Cheng et al (16) reported that elevated levels of miR-141 were associated with liver metastasis of CRC in a 
Table I. Sensitivity and specificity of main serum microRNAs for colorectal cancer diagnosis.

\begin{tabular}{llll}
\hline miRNA & Sensitivity (stage) & Specificity (stage) & Authors (Refs.) \\
\hline miR-92 & $89 \%$ & $70 \%$ & Ng et al (14) \\
miR-141 & $90.9 \%$ (IV vs. I/II) & $77.1 \%$ (IV vs. I/II) & Cheng et al (16) \\
& $77.1 \%$ (IV vs. III) & $89.7 \%$ (IV vs. III) & \\
miR-29a & $77.1 \%$ (IV vs. I-III) & $89.7 \%$ (IV vs. I-III) & Huang et al (15) \\
miR-21 & $69 \%$ & $89.1 \%$ & Wang et al $(19)$ \\
miR-221 & $84.5 \%$ & $74.4 \%$ & Pu et al $(21)$ \\
miR-601 & $86 \%$ & $41 \%$ & Wang et al $(22)$ \\
miR-760 & $69.2 \%$ & $72.4 \%$ & Wang et al $(22)$ \\
\hline
\end{tabular}

study on $102 \mathrm{CRC}$ samples and 54 controls. They investigated the serum levels of miR-21, miR-92 and miR-141. The plasma levels of miR-141 were found to be highly correlated with the TNM stage of CRC. Receiver operating characteristic (ROC) curve analysis demonstrated that plasma miR-141 had a $90.9 \%$ sensitivity and a $77.1 \%$ specificity in differentiating stage IV from stage I-II cases with an area under the curve (AUC) of 0.861 , a $77.1 \%$ sensitivity and an $89.7 \%$ specificity in differentiating stage IV and III cases with an AUC of 0.803 and a $77.1 \%$ sensitivity and an $89.7 \%$ specificity in differentiating stage IV and combined stage I-III cases with an AUC of 0.836. The combination of miR-141 levels with carcinoembryonic antigen (CEA) levels improved the accuracy of CRC diagnosis. The results indicated that plasma miR-141 may be a novel biomarker in the detection of CRC with distant metastasis.

miR-29a. Huang et al (15) conducted a study with plasma samples from 100 patients with CRC, 37 with adenoma and 59 healthy individuals. They identified 12 miRNAs with upregulated expression, including miR-134, miR-146a, miR-17-3p, miR-181d, miR-191, miR-221, miR-222, miR-223, miR-25, miR-29a, miR-320a and miR-92a. The sensitivity of miR-29a was $69 \%$ and its specificity was $89.1 \%$ for CRC. Tumor-derived plasma miR-29a is a potential CRC diagnostic marker. It was proven that there is an association between miR-29a and CRC TNM stage. In addition, another study detected that serum miR-29a levels were significantly higher in CRC with liver metastasis compared to CRC patients, exhibiting a sensitivity of $75 \%$ and a specificity of $75 \%$ (AUC of 0.803 at a cut-off of 0.155 ) in differentiating metastatic from non-metastatic patients (17).

$m i R-21$. Asangani et al (18) demonstrated that tumor suppressor gene Pdcd4 was downregulated by miR-21 in CRC cell lines. It was also considered of value to investigate miR-21 expression in the serum of CRC patients. In their study, Wang et al (19) detected the expression of circulating miR-21 in 174 patients with solid cancers, including breast, esophageal, gastric, colorectal and lung cancer, and in 39 controls. miR-21 was significantly overexpressed in human solid cancer serum compared to control serum $(\mathrm{P}<0.001)$. The sensitivity and specificity of miR-21 in the diagnosis of CRC were 84.5 and $74.4 \%$, respectively (19). Kanaan et al (20) also showed that miR-21 differentiated CRC patients from controls with a
90\% specificity and sensitivity. Therefore, serum miR-21 may serve as a potential broad-spectrum serum-based biomarker for the detection of CRC.

$m i R-221$. Pu et al (21) assessed plasma miR-21, miR-221 and miR-222 levels in 103 CRC patients and 37 controls. The ROC analysis revealed that the level of miR-221 is a potential biomarker for differentiating CRC patients from controls and is correlated with p53 expression. The sensitivity of miR-221 was $86 \%$ with a specificity of $41 \%$ for CRC. Therefore, serum miR-221 was approved as a potential non-invasive molecular marker for the diagnosis of CRC.

Other miRNAs. Other serum miRNAs associated with CRC diagnosis have been also identified. A previous study by Wang et al (22) aimed to identify novel serum miRNAs that may be used as biomarkers for the detection of CRC. They observed that miR-601 and miR-760 were downregulated in CRC plasma. The ROC analysis demonstrated a $69.2 \%$ sensitivity and $72.4 \%$ specificity of miR-601 (AUC=0.747) and an $80.0 \%$ sensitivity and $72.4 \%$ specificity of miR-760 (AUC=0.788) for the early detection of CRC. Serum miR-601 and miR-760 levels in CRC were significantly decreased, suggesting the possibility of serum miR-601 and miR-760 as novel biomarkers for the clinical diagnosis of CRC.

\section{Mechanism of miRNA secretion and incorporation}

Several studies have explained the mechanisms of action of various miRNAs in CRC. Overexpression or downregulation of specific miRNAs were proven to be correlated with carcinogenesis and metastasis $(23,24)$. However, the secretory mechanism and incorporation of extracellular miRNAs in CRC cells has not been elucidated.

In certain organisms, such as C. elegans and Drosophila melanogaster, small RNA pathways may spread from cell to cell. In mammalian cells, recent studies demonstrated the importance of communication between cancer cells and their surroundings through exosomes $(25,26)$. Kosaka et al $(27)$ suggested that miRNAs are released through a neutral sphingomyelinase 2 (nSM-ase2)-mediated ceramide-dependent secretory machinery. The secretory miRNAs are transferable and functional in the recipient cells. The nSM-ase2, which regulates ceramide biosynthesis, may control the secretion of 
miRNAs outside the cells. This enzyme is already known for the secretion of exosomes. Another possible mechanism for the secretion of miRNAs involves an apoptotic body, specifically the membranous microvesicles shed from cells during apoptosis (28). A study conducted by Zernecke et al (28) demonstrated that endothelial cell-derived apoptotic bodies conveyed paracrine alarm signals to recipient cells, which triggered the production of chemokine CXC motif ligand 12 (CXCL12). CXCL12 production was mediated by miR-126. miR-126 was enriched in apoptotic bodies and repressed its target gene in recipient cells. The study also showed that apoptotic bodies may transfer miRNAs between the cells. Of note, it was previously found that phosphatidylserine was detected on the surface of exosomes and apoptotic bodies. Miyanishi et al (29) identified an antibody that inhibits the phosphatidylserine-dependent engulfment of apoptotic cells and this antibody may also be involved in exosome-mediated intercellular signaling. Although the mechanism of secretion and incorporation of miRNAs has not been elucidated, secretory miRNAs may play a pivotal role as signaling molecules in physiological and pathological events.

\section{Potential value}

The mortality and morbidity of CRC have moderately declined and $\mathrm{CRC}$ has become a preventable disease, provided the lesions are detected early with screening methods (30). Therefore, an effective diagnostic method should be applied for the clinical detection of CRC.

The fecal occult blood test (FOBT) is the most widely used screening modality for CRC. It was reported that the sensitivity of a single FOBT for CRC is $30-50 \%$ (31) and its specificity for CRC and adenomas is $90-98 \%$ (32). Therefore, one of the potential limitations is overdiagnosis. In addition, ingestion of certain foods (red meat, certain fruits and vegetables) and medicines (non-steroidal anti-inflammatory drugs) may yield false-positive results and multiple stool samples may be required.

CEA is the most widely used serum marker in patients with CRC; however, CEA may also be elevated by benign conditions. For example, cirrhosis, inflammatory bowel disease, chronic lung disease and pancreatitis may result in increased blood CEA levels (33). The specificity of CEA in the identification of occult CRC is high, however, findings of other studies have shown its sensitivity to be extremely low (34). Accordingly, the use of CEA is not recommended for mass screening (35).

Certain miRNAs exhibit significantly up- or downregulated levels in the plasma of CRC patients (Table I). The studies shown in Table I $(14-16,19,21,22)$ indicated that the investigated miRNAs exhibited higher sensitivity and specificity. Serum miRNAs are resistant to digestion by RNase A and are notably stable under other diverse conditions, such as boiling, low/high $\mathrm{pH}$, extended storage and freeze-thaw cycles (36). Serum miRNAs are not affected by the location or blood loss of the neoplasms. Furthermore, they show promise as potential biomarkers with a high stability. Several current studies suggest that deregulation of miRNAs is closely linked to cancer incidence (37). Therefore, it is anticipated that circulating serum miRNAs may become novel methods for reducing the false-positive and false-negative results of the conventional diagnostic methods (10).

\section{Limitations}

Biomarkers capable of detecting TNM stage I or II cancers may bear the highest potential for reducing the mortality and overall health burden caused by CRC. However, the association between serum miRNAs and the early stage of CRC was seldom revealed by previous studies. In addition, the application of serum miRNAs is associated with a high cost and a long latency time, which may limit screening for a wide range of patients (38).

The availability of data regarding the association of age and health status with the dynamic changes of the serum from different CRC patients is currently limited. As a result, it may be necessary to include a wide number of CRC patients exhibiting factors such as comorbidities and lifestyle variations, which may modify the miRNA levels (39).

\section{Conclusions}

The identification of serum miRNAs has significantly altered the view on gene regulation and the different serum miRNA expressions have attested the presence of CRC. Additional studies should focus on early-stage CRC detection and evaluation of disease progression following surgery (40). Premalignant lesion (e.g., adenoma) detection by serum miRNAs is more valuable for CRC prevention. Furthermore, investigation of the mechanisms underlying miRNA secretion and the dynamic progress of miRNAs in the circulation is necessary. It is recommended that prospective studies are replicated in a number of large independent populations to evaluate the feasibility of their results. A combination of biomarkers may improve the diagnostic accuracy. Therefore, it may be useful to evaluate the combination of the microRNA diagnostic biomarker with other available screening tests. A moderate number of miRNAs may be sufficient to differentiate cancerous from normal tissue, taking into consideration practice value and cost.

\section{Acknowledgements}

This study was supported by the Shanghai Young Doctor Training Plan and a grant from the Major Research and Development Project of Innovative Drugs, Ministry of Science and Technology (no. 2012ZX09303004-001).

\section{References}

1. Jemal A, Siegel R, Ward E, Hao Y, Xu J and Thun MJ: Cancer statistics. CA Cancer J Clin 59: 225-249, 2009.

2. Ferlay J, Shin HR, Bray F, Forman D, Mathers C and Parkin DM: Estimates of worldwide burden of cancer in 2008: GLOBOCAN 2008. Int J Cancer 127: 2893-2917, 2010.

3. Walsh JM and Terdiman JP: Colorectal cancer screening: scientific review. JAMA 289: 1288-1296, 2003.

4. Bartel DP: MicroRNAs: genomics, biogenesis, mechanism, and function. Cell 116: 281-297, 2004.

5. Visone R and Croce CM: MiRNAs and cancer. Am J Pathol 174: 1131-1138, 2009.

6. Slaby O, Svoboda M, Michalek J and Vyzula R: MicroRNAs in colorectal cancer: translation of molecular biology into clinical application. Mol Cancer 8: 102, 2009. 
7. Chim SS, Shing TK, Hung EC, Leung TY, Lau TK, Chiu RW and Lo YM: Detection and characterization of placental microRNAs in maternal plasma. Clin Chem 54: 482-490, 2008.

8. Lawrie CH, Gal S, Dunlop HM, Pushkaran B, Liggins AP, Pulford K, Banham AH, Pezzella F, Boultwood J, Wainscoat JS, Hatton CS and Harris AL: Detection of elevated levels of tumour-associated microRNAs in serum of patients with diffuse large B-cell lymphoma. Br J Haematol 141: 672-675, 2008.

9. Wong TS, Liu XB, Wong BY, Ng RW, Yuen AP and Wei WI: Mature miR-184 as potential oncogenic microRNA of squamous cell carcinoma of tongue. Clin Cancer Res 14: 2588-2592, 2008.

10. Kosaka N, Iguchi H and Ochiya T: Circulating microRNA in body fluid: a new potential biomarker for cancer diagnosis and prognosis. Cancer Sci 101: 2087-2092, 2010.

11. Calin CA and Croce CM: MicroRNA signatures in human cancers. Nat Rev Cancer 6: 857-866, 2006.

12. Calin GA, Ferracin M, Cimmino A, Di Leva G, Shimizu M, Wojcik SE, Iorio MV, Visone R, Sever NI, Fabbri M, Iuliano R, Palumbo T, Pichiorri F, Roldo C, Garzon R, Sevignani C, Rassenti L, Alder H, Volinia S, Liu CG, Kipps TJ, Negrini M and Croce CM: A microRNA signature associated with prognosis and progression in chronic lymphocytic leukemia. N Engl J Med 353: 1793-1801, 2005.

13. Schetter AJ, Leung SY, Sohn JJ, Zanetti KA, Bowman ED, Yanaihara N, Yuen ST, Chan TL, Kwong DL, Au GK, Liu CG, Calin GA, Croce CM and Harris CC: MicroRNA expression profiles associated with prognosis and therapeutic outcome in colon adenocarcinoma. JAMA 299: 425-436, 2008.

14. Ng EK, Chong WW, Jin H, Lam EK, Shin VY, Yu J, Poon TC, $\mathrm{Ng}$ SS and Sung JJ: Differential expression of microRNAs in plasma of patients with colorectal cancer: a potential marker for colorectal cancer screening. Gut 58: 1375-1381, 2009.

15. Huang Z, Huang D, Ni S, Peng Z, Sheng W and Du X: Plasma microRNAs are promising novel biomarkers for early detection of colorectal cancer. Int J Cancer 127: 118-126, 2010.

16. Cheng H, Zhang L, Cogdell DE, Zheng H, Schetter AJ, Nykter M, Harris CC, Chen K, Hamilton SR and Zhang W: Circulating plasma MiR-141 is a novel biomarker for metastatic colon cancer and predicts poor prognosis. PLoS One 6: e17745, 2011.

17. Wang LG and Gu J: Serum microRNA-29a is a promising novel marker for early detection of colorectal liver metastasis. Cancer Epidemiol 36: e61-e67, 2012.

18. Asangani IA, Rasheed SA, Nikolova DA, Leupold JH, Colburn NH, Post S and Allgayer H: MicroRNA-21 (miR-21) post-transcriptionally downregulates tumor suppressor Pdcd4 and stimulates invasion, intravasation and metastasis in colorectal cancer. Oncogene 27: 2128-2136, 2008.

19. Wang B and Zhang Q: The expression and clinical significance of circulating microRNA-21 in serum of five solid tumors. J Cancer Res Clin Oncol 138: 1659-1666, 2012.

20. Kanaan Z, Rai SN, Eichenberger MR, Roberts H, Keskey B, Pan J and Galandiuk S: Plasma miR-21: a potential diagnostic marker of colorectal cancer. Ann Surg 256: 544-551, 2012.

21. Pu XX, Huang GL, Guo HQ, Guo CC, Li H, Ye S, Ling S, Jiang L, Tian Y and Lin TY: Circulating miR-221 directly amplified from plasma is a potential diagnostic and prognostic marker of colorectal cancer and is correlated with p53 expression. J Gastroenterol Hepatol 25: 1674-1680, 2010.

22. Wang Q, Huang Z, Ni S, Xiao X, Xu Q, Wang L, Huang D, Tan C, Sheng W and Du X: Plasma miR-601 and miR-760 are novel biomarkers for the early detection of colorectal cancer. PLoS One 7: e44398, 2012.

23. Fang Y, Xue JL, Shen Q, Chen J and Tian L: MicroRNA-7 inhibits tumor growth and metastasis by targeting the phosphoinositide 3-kinase/Akt pathway in hepatocellular carcinoma. Hepatology 55: 1852-1862, 2012.
24. Li X, Zhang Y, Zhang H, Liu X, Gong T, Li M, Sun L, Ji G, Shi Y, Han Z, Han S, Nie Y, Chen X, Zhao Q, Ding J, Wu K and Daiming F: miRNA-223 promotes gastric cancer invasion and metastasis by targeting tumor suppressor EPB41L3. Mol Cancer Res 9: 824-833, 2011.

25. Skog J, Würdinger T, van Rijn S, Meijer DH, Gainche L, Sena-Esteves M, Curry WT Jr, Carter BS, Krichevsky AM and Breakefield XO: Glioblastoma microvesicles transport RNA and proteins that promote tumour growth and provide diagnostic biomarkers. Nat Cell Biol 10: 1470-1476, 2008.

26. Wolfers J, Lozier A, Raposo G, Regnault A, Théry C, Masurier C, Flament C, Pouzieux S, Faure F, Tursz T, Angevin E, Amigorena S and Zitvogel L: Tumor-derived exosomes are a source of shared tumor rejection antigens for CTL cross-priming. Nat Med 7: 297-303, 2001

27. Kosaka N, Iguchi H, Yoshioka Y, Takeshita F, Matsuki Y and Ochiya T: Secretory mechanisms and intercellular transfer of microRNAs in living cells. J Biol Chem 285: 17442-17452, 2010.

28. Zernecke A, Bidzhekov K, Noels H, Shagdarsuren E, Gan L, Denecke B, Hristov M, Köppel T, Jahantigh MN, Lutgens E, Wang S, Olson EN, Schober A and Weber C: Delivery of microRNA-126 by apoptotic bodies induces CXCL12-dependent vascular protection. Sci Signal 2: ra81, 2009.

29. Miyanishi M, Tada K, Koike M, Uchiyama Y, Kitamura T and Nagata S: Identification of Tim 4 as a phosphatidylserine receptor. Nature 450: 435-439, 2007.

30. Lieberman DA: Clinical practice. Screening for colorectal cancer. N Engl J Med 361: 1179-1187, 2009.

31. Graser A, Stieber P, Nagel D, Schäfer C, Horst D, Becker CR, Nikolaou K, Lottes A, Geisbüsch S, Kramer H, Wagner AC, Diepolder H, Schirra J, Roth HJ, Seidel D, Göke B, Reiser MF and Kolligs FT: Comparison of CT colonography, colonoscopy, sigmoidoscopy and faecal occult blood tests for the detection of advanced adenoma in an average risk population. Gut 58: 241-248, 2009.

32. Duffy MJ, van Dalen A, Haglund C, Hansson L, Holinski-Feder E, Klapdor R, Lamerz R, Peltomaki P, Sturgeon C and Topolcan O: Tumour markers in colorectal cancer: European Group on Tumour Markers (EGTM) guidelines for clinical use. Eur J Cancer 43: 1348-1360, 2007.

33. Spratlin JL, Hui D, Hanson J, Butts C and Au HJ: Community compliance with carcinoembryonic antigen: follow-up of patients with colorectal cancer. Clin Colorectal Cancer 7: $118-125,2008$

34. Eleftheriadis N, Papaloukas C and Pistevou-Gompaki K: Diagnostic value of serum tumor markers in asymptomatic individuals. J BUON 14: 707-710, 2009.

35. Amayo AA and Kuria JG: Clinical application of tumour markers: a review. East Afr Med J 86: S76-S83, 2009.

36. Ahmed FE, Vos PW, Jeffries C, Wiley JE, Weidner DA, Mota H, Bonnerup C, Sibata C and Allison RR: Differences in mRNA and microRNA microarray expression profiles in human colon adenocarcinoma HT-29 cells treated with either intensity-modulated radiation therapy (IMRT), or conventional radiation therapy (RT). Cancer Genomics Proteomics 6: 109-127, 2009.

37. Sassen S, Miska EA and Caldas C: MicroRNA: implications for cancer. Virchows Arch 452: 1-10, 2008.

38. Brase JC, Wuttig D, Kuner R and Sültmann H: Serum microRNAs as non-invasive biomarkers for cancer. Mol Cancer 9: 306, 2010

39. Luo X, Burwinkel B, Tao S and Brenner H: MicroRNA signatures: novel biomarker for colorectal cancer? Cancer Epidemiol Biomarkers Prev 20: 1272-1286, 2011.

40. Wu WK, Law PT, Lee CW, Cho CH, Fan D, Wu K, Yu J and Sung JJ: MicroRNA in colorectal cancer: from benchtop to bedside. Carcinogenesis 32: 247-253, 2011. 